\title{
A Semi-Empirical Method for the Estimation of the Hydration Number of Mn(II)-Complexes
}

\author{
Joop A. Peters ${ }^{1, *(1)}$ and Carlos F. G. C. Geraldes ${ }^{2, *}$ \\ 1 Laboratory of Biocatalysis, Delft University of Technology, Van der Maasweg 9, \\ 2629 HZ Delft, The Netherlands \\ 2 Department of Life Sciences and Coimbra Chemistry Centre, Faculty of Science and Technology, \\ University of Coimbra, Calçada Martim de Freitas, 3000-456 Coimbra, Portugal \\ * Correspondence: j.a.peters@tudelft.nl (J.A.P.); geraldes@ci.uc.pt (C.F.G.C.G.); \\ Tel.: +351-239-240-730 (C.F.G.C.G.)
}

Received: 13 September 2018; Accepted: 24 October 2018; Published: 26 October 2018

\begin{abstract}
A semi-empirical equation to estimate the hydration number of $\mathrm{Mn}$ (II) complexes was derived from a database of 49 previously published ${ }^{1} \mathrm{H}$ longitudinal Nuclear Magnetic Relaxation Dispersion profiles. This equation has the longitudinal ${ }^{1} \mathrm{H}$ relaxivity and the molecular weight of the $\mathrm{Mn}(\mathrm{II})$ complex under consideration as parameters.
\end{abstract}

Keywords: relaxivity; inner-sphere water molecules; NMRD profile

\section{Introduction}

During the last decades, $\mathrm{Gd}^{3+}$-chelates, such as Gd-DTPA (DTPA = diethylenetriamine$N, N, N^{\prime}, N^{\prime \prime}, N^{\prime \prime}, N^{\prime \prime \prime}$-pentaacetate) and Gd-DOTA (DOTA = 1,4,7,10-tetraazacyclododecane- $N, N^{\prime}, N^{\prime \prime}, N^{\prime \prime \prime}-$ tetraacetate), have become indispensable tools for the contrast enhancement of magnetic resonance images [1-3]. These contrast agents (CAs) have proven to be generally extremely safe; only $0.03 \%$ of all administrations (about 100 million worldwide) gave rise to serious adverse effects. However, during recent years, some concerns have arisen because of (i) incidents of nephrogenic systemic fibrosis (NSF) associated with $\mathrm{Gd}^{3+}$-complexes of linear DTPA derivates and (ii) observation of Gd-accumulation in the brains of patients with normal renal function, after repeated administrations of DTPA-type of CAs [4-8]. Both effects may be ascribed to the relative kinetic instability of $\mathrm{Gd}^{3+}$ complexes of linear polyaminocarboxylates. The concerns about Gd-based CAs have led to an increased interest in application of $\mathrm{Gd}^{3+}$-free CAs. High spin $d^{5} \mathrm{Mn}^{2+}$ is an attractive alternative for $f^{7} \mathrm{Gd}^{3+}$, because it has only two less unpaired electrons, whereas a high electronic symmetry is favorable for high relaxivities. Moreover, $\mathrm{Mn}^{2+}$ is less toxic than $\mathrm{Gd}^{3+}$, as reflected in its important role as a cofactor in many enzymatic reactions, including the anti-oxidant enzyme superoxide dismutase, as well as in enzymes involved in neurotransmitter synthesis and metabolism in the brain. However, the concentration of free $\mathrm{Mn}^{2+}$ in organisms is very low, for instance $0.3-1 \mu \mathrm{g} \cdot \mathrm{L}^{-1}$ in human blood [9]. High concentrations are neurotoxic, and therefore, $\mathrm{Mn}^{2+}$ preferably needs to be sequestered for safe application as $\mathrm{CA}$ in humans. Due to its lower charge, complexes are usually less stable than their $\mathrm{Gd}^{3+}$-counterparts. It is important to assure that the dissociation of $\mathrm{Mn}^{2+}$-based CAs is minimized in order to avoid any neurotoxic side effects. On the other hand, the relaxation rate enhancing efficacy should be as high as possible in view of the inherently low sensitivity of magnetic resonance imaging (MRI) CAs. Finding a balance between kinetic stability and optimal sensitivity is a challenge during the design of novel $\mathrm{Mn}^{2+}$-based CAs.

The efficacy of a CA is usually expressed by its relaxivity, the longitudinal, or transverse relaxation rate enhancement normalized for a solution containing $1 \mathrm{mM}$ of paramagnetic metal ions $\left(r_{1}\right.$ and 
$r_{2}$, respectively). One of the most important parameters governing the longitudinal relaxivity $\left(r_{1}\right)$ of paramagnetic CAs is the number of water molecules in the first coordination sphere of the metal ion $(q)$, since the inner sphere contribution to $r_{1}$ is linearly proportional to it. Several good methods are available to evaluate $q$ for $\mathrm{Gd}^{3+}$-based CAs, including measurements of lanthanide induced ${ }^{17} \mathrm{O}$ NMR shifts (NMR = Nuclear Magnetic Resonance) of water $[1,10,11]$, determination of the ${ }^{17} \mathrm{O}$ scalar coupling constant $\left(A_{\mathrm{O}} / \hbar\right)$ from simultaneous fitting of ${ }^{17} \mathrm{O}$ shift and/or relaxation data and ${ }^{1} \mathrm{H}$ NMRD data (NMRD = Nuclear Magnetic Relaxation Dispersion), and comparison of the luminescence decay rates of $\mathrm{Eu}^{3+}$ or $\mathrm{Tb}^{3+}$ complexes in $\mathrm{H}_{2} \mathrm{O}$ and $\mathrm{D}_{2} \mathrm{O}$ [12]. The determination of $q$ for $\mathrm{Mn}^{2+}$-complexes is more challenging. The luminescence decay method is impossible, because the complexes are not luminescent. ${ }^{17} \mathrm{O}$ NMR methods are more ambiguous since they rely on the assumption that $A_{\mathrm{O}} / \hbar$ is almost independent on the coordination environment of $\mathrm{Mn}^{2+}$, which appears not to be case: values in the range $-(26-73) \times 10^{6} \mathrm{rad} \cdot \mathrm{s}^{-1}$ have been evaluated from ${ }^{17} \mathrm{O}$ NMR measurements on $\mathrm{Mn}^{2+}$ complexes (see below, Table 1). Esteban-Gómez et al. have estimated by DFT calculations that variations of $\mathrm{Mn}-\mathrm{O}$ distances and dihedral angles among these complexes may lead to $A_{\mathrm{O}} / \hbar$ values ranging between 30 and $58 \times 10^{6} \mathrm{rad} \cdot \mathrm{s}^{-1}$ [13]. By contrast, the range of $A_{\mathrm{O}} / \hbar$ values observed for $\mathrm{Gd}^{3+}$-complexes observed is narrower $\left(-(3.6-4.2) \times 10^{6} \mathrm{rad} \cdot \mathrm{s}^{-1}\right)$ [11], allowing reasonable accurate estimations of $q$ using a ${ }^{17} \mathrm{O}$ NMR shift and/or relaxation rates. Moreover, accurate $\mathrm{Mn}^{2+}$-induced shift measurements are difficult because of the very large line broadenings and relatively small induced shifts.

X-ray crystallography may provide structures of $\mathrm{Mn}^{2+}$ complexes in the solid state, but these structures are not necessarily the same in solution. Frequently dimeric or oligomeric assemblies occur in crystal structures, which will dissociate upon dissolution in water. Often, a value of $q$ is estimated based on the denticity of the organic ligand and assuming a total $\mathrm{Mn}^{2+}$-coordination number of 6 . However, high spin $\mathrm{Mn}^{2+}$-complexes have almost no ligand stabilization energy, and consequently, do not show a clear preference for a specific coordination number. Others use the magnitudes of the longitudinal relaxivities to estimate $q$, which is ambiguous as well, as will be demonstrated below. Recently, Póta et al. suggested that DFT calculations (at the M062X/TZVP level) may provide reliable $q$-values [14]; however, these calculations require excessive amounts of computing time with supercomputers.

Here, we will demonstrate that reliable $q$ values for $\mathrm{Mn}^{2+}$-complexes can be obtained from experimental $r_{1}$ values at low Larmor frequencies $(L F)$ and the formula weight $(F W)$ of the complexes.

\section{Results and Discussion}

A database of 49 previously published ${ }^{1} \mathrm{H}$ longitudinal Nuclear Magnetic Relaxation Dispersion profiles (plots of $r_{1}$ versus $L F$ ) was constructed (see Table 1 and Figure 1). The relaxivity has an inner-sphere contribution by water molecules exchanging between the first coordination sphere of the metal ion and the bulk $\left(r_{\mathrm{i}, \mathrm{IS}}\right)$ and an outer-sphere contribution due to water molecules in the bulk that diffuse in the surroundings of the metal ion without being bound to it $\left(r_{1, \mathrm{OS}}\right)$ (see Equation (1)). The amount of a $\mathrm{Mn}^{2+}$-based CA needed is always very small (in the $\mathrm{mM}$ range) and the $\mathrm{Mn}^{2+}$-induced chemical shifts of the water protons are negligible. Under those conditions, $r_{1, \mathrm{IS}}$ was related to the longitudinal relaxation time of a $\mathrm{Mn}^{2+}$-bound water molecule $\left(T_{1 \mathrm{M}}\right)$, according to Equation (2) $[15,16]$ :

$$
\begin{gathered}
r_{1}=r_{1, \mathrm{IS}}+r_{1, \mathrm{OS}} \\
r_{1, \mathrm{IS}}=\frac{q}{55556\left(T_{1 \mathrm{M}}+\tau_{\mathrm{M}}\right)}
\end{gathered}
$$

Here, $\tau_{M}$ is the residence time of a water molecule in the first coordination sphere of $\mathrm{Mn}^{2+}$. Since the electronic relaxation time $\left(T_{1 \mathrm{e}}\right)$ for $\mathrm{Mn}^{2+}$-complexes was generally larger than the rotational correlation time $\left(\tau_{R}\right)$, the contribution of the Curie relaxation mechanism to the longitudinal relaxation was negligible; only the dipolar and the scalar mechanisms needed to be taken into 
consideration. These contributions $\left(T_{1 \mathrm{M}, \mathrm{DD}}{ }^{-1}\right.$ and $T_{1 \mathrm{M}, \mathrm{SC}}{ }^{-1}$, respectively) may be estimated by using the Solomon-Bloembergen-Morgan (SBM) equations (Equations (3)-(7)) [17,18]:

$$
\begin{gathered}
\frac{1}{T_{1 \mathrm{M}}}=\frac{1}{T_{1 M, D D}}+\frac{1}{T_{1 M, S C}} \\
\frac{1}{T_{1, D D}}=\frac{2}{15}\left(\frac{\mu_{0}}{4 \pi}\right)^{2} \frac{\hbar^{2} \gamma_{\mathrm{S}}^{2} \gamma_{\mathrm{I}}^{2}}{r_{\mathrm{MnH}}^{6}} S(S+1)\left(\frac{3 \tau_{\mathrm{d} 1}}{1+\omega_{\mathrm{I}}^{2} \tau_{\mathrm{d} 1}^{2}}+\frac{7 \tau_{\mathrm{d} 2}}{1+\omega_{\mathrm{S}}^{2} \tau_{\mathrm{d} 2}^{2}}\right) \\
\frac{1}{T_{1, S C}}=\frac{S(S+1)}{3}\left(\frac{A_{H}}{h}\right)^{2}\left(\frac{2 \tau_{s 2}}{1+\omega_{s}^{2} \tau_{s 2}^{2}}\right)
\end{gathered}
$$

Here, $\left(\mu_{0} / 4 \pi\right)$ is the magnetic permeability in vacuum, $r_{\mathrm{MnH}}$ is the distance between $\mathrm{Mn}^{2+}$ and the $\mathrm{H}$-atom of a bound water molecule, $S$ is the electron spin $\left(S=5 / 2\right.$ for $\left.\mathrm{Mn}^{2+}\right), \gamma_{\mathrm{I}}$ is the ${ }^{1} \mathrm{H}$ nuclear gyromagnetic ratio, $\gamma_{S}$ is the electron gyromagnetic ratio, and $\omega_{\mathrm{I}}$ and $\omega_{\mathrm{S}}$ are the Larmor frequencies of the proton and electron spin, respectively, $A_{\mathrm{H}} / \hbar$ is the hyperfine coupling constant between $\mathrm{Mn}^{2+}$ and the bound water proton, $\tau_{\mathrm{di}}{ }^{-1}=\tau_{\mathrm{M}}{ }^{-1}+\tau_{\mathrm{R}}{ }^{-1}+T_{\mathrm{ie}}{ }^{-1}$, and $\tau_{\mathrm{s} 2}{ }^{-1}=\tau_{\mathrm{M}}{ }^{-1}+T_{2 \mathrm{e}}{ }^{-1}$. The electronic relaxation times are often interpreted in terms of the zero-field splitting (ZFS) interaction using Equations (6) and (7) [19]:

$$
\begin{gathered}
\frac{1}{T_{1 \mathrm{e}}}=\frac{1}{25} \Delta^{2} \tau_{\mathrm{v}}[4 S(S+1)-3]\left(\frac{1}{1+\omega_{\mathrm{s}}^{2} \tau_{\mathrm{v}}^{2}}+\frac{4}{1+4 \omega_{\mathrm{s}}^{2} \tau_{\mathrm{v}}^{2}}\right) \\
\frac{1}{T_{2 \mathrm{e}}}=\frac{1}{50} \Delta^{2} \tau_{\mathrm{v}}[4 S(S+1)-3]\left(\frac{5}{1+\omega_{\mathrm{s}}^{2} \tau_{\mathrm{v}}^{2}}+\frac{2}{1+4 \omega_{\mathrm{s}}^{2} \tau_{\mathrm{v}}^{2}}+3\right)
\end{gathered}
$$

In these equations, $\Delta^{2}$ represents the mean-squared fluctuation of the ZFS, and $\tau_{\mathrm{v}}$ is the correlation time for the instantaneous distortion of the coordination polyhedron of $\mathrm{Mn}^{2+}$. From these equations, it can be derived that the low field limiting value of the longitudinal and transverse electronic relaxation rates $\left(\tau_{\mathrm{S}_{0}}{ }^{-1}\right)$ were equal, given by Equation $(8)$ :

$$
\frac{1}{\tau_{S 0}}=\frac{1}{5} \Delta^{2} \tau_{\mathrm{v}}[4 S(S+1)-3]
$$

The outer-sphere contribution to the relaxivity $\left(r_{1, \mathrm{OS}}\right)$ is described by Equations (9) and (10) [20]:

$$
\begin{aligned}
& r_{1, \mathrm{OS}}=\left(\frac{32 \pi}{405}\right)\left(\frac{\mu_{0}}{4 \pi}\right)^{2} \gamma_{\mathrm{I}}^{2} \gamma_{\mathrm{S}}^{2} \hbar^{2} S(S+1) \frac{N_{\mathrm{A}}}{a_{\mathrm{MnH}} D_{\mathrm{MnH}}}\left[3 J_{\mathrm{OS}}\left(\omega_{\mathrm{I}}, T_{1 \mathrm{e}}\right)+7 J_{\mathrm{OS}}\left(\omega_{\mathrm{S}}, T_{2 \mathrm{e}}\right)\right] \\
& J_{\mathrm{OS}}\left(\omega, T_{\mathrm{je}}\right)=\operatorname{Re}\left\{\frac{1+\frac{1}{4}\left[i \omega \tau_{\mathrm{MnH}}+\left(\frac{\tau_{\mathrm{MnH}}}{T_{\mathrm{je}}}\right)\right]^{\frac{1}{2}}}{1+\left[i \omega \tau_{\mathrm{MnH}}+\left(\frac{\tau_{\mathrm{MnH}}}{T_{\mathrm{je}}}\right)\right]^{\frac{1}{2}}+\frac{4}{9}\left[i \omega \tau_{\mathrm{MnH}}+\left(\frac{\tau_{\mathrm{MNH}}}{T_{\mathrm{je}}}\right)\right]+\frac{1}{9}\left[i \omega \tau_{\mathrm{MnH}}+\left(\frac{\tau_{\mathrm{MnH}}}{T_{\mathrm{je}}}\right)\right]^{\frac{3}{2}}}\right\}
\end{aligned}
$$

Here, $N_{\mathrm{A}}$ is Avogadro's number, $a_{\mathrm{MnH}}$ is the distance of closest approach of a diffusing water molecule to $\mathrm{Mn}^{2+}, D_{\mathrm{MnH}}$ stands for the diffusion coefficient, and $J_{\mathrm{os}}\left(\omega, T_{\mathrm{je}}\right)(j=1,2)$ are spin density functions. The diffusion correlation time $\left(\tau_{\mathrm{MnH}}\right)$ is given by $a_{\mathrm{MnH}^{2}} / D_{\mathrm{MnH}}$.

An inspection of Equations (4) and (5) indicates that in an NMRD profile, two inflection points may be expected: one originating from $1 / T_{1, \mathrm{DD}}$ when $\omega \tau_{\mathrm{d} 2}=1$ (at $L F \approx 10 \mathrm{MHz}$ ), and another one due to $1 / T_{1, \mathrm{SC}}$ when $\omega \tau_{\mathrm{S} 2}=1$ (at $L F \approx 0.06 \mathrm{MHz}$ ) [21,22]. Until now, only two $\mathrm{Mn}^{\mathrm{II}}$-based CAs have been observed that have NMRD profiles showing these two inflection points: $\left[\mathrm{Mn}^{\mathrm{II}}\left(\mathrm{H}_{2} \mathrm{O}\right)_{6}\right]^{2+}[21,22]$ and $\left[\mathrm{Mn}_{2}{ }_{2}(\mathrm{ENOTA})\left(\mathrm{H}_{2} \mathrm{O}\right)_{2}\right]$ [23]. All other reported NMRD profiles display only the high field dispersion at $L F \approx 10 \mathrm{MHz}$, indicating that for these compounds the contribution of the scalar interaction to the relaxivity is negligible. 
It should be noted that the SBM equations, particularly Equations (6) and (7), only hold under certain conditions, such as (i) the Redfield condition of extreme narrowing $\left(\Delta_{\mathrm{S}} \tau_{\mathrm{RH}}<<1, \Delta_{\mathrm{S}}\right.$ is the static ZFS), (ii) the ZFS energy should be much larger than the Zeeman energy ( $\left.E_{\text {ZFS }} \gg>E_{\text {Zeeman }}\right)$, (iii) the electronic decay should be mono-exponential [24,25]. Outside these limits, a proper description of the electronic relaxation requires more complicated calculations that also take the static ZFS into account. Although the conditions for applying the SBM theory for the modeling of NMRD profiles are not always valid for $\mathrm{Mn}^{2+}$ complexes, this theory has been applied in almost all studies on the complexes mentioned in Table 1. It may be justified if the Redfield condition applies and if only data for $L F>10 \mathrm{MHz}$ were considered [26], because then the influence of the electronic relaxation can be neglected. Otherwise, the SBM model can be applied for a qualitative description of structure relaxivity relationships when the best fit parameters obtained, particularly those concerning the electronic relaxation, are considered as effective rather than physically relevant [27]. The most relevant parameters governing the relaxivity as determined by fitting of NMRD profiles with the SBM equations are included in Table 1.

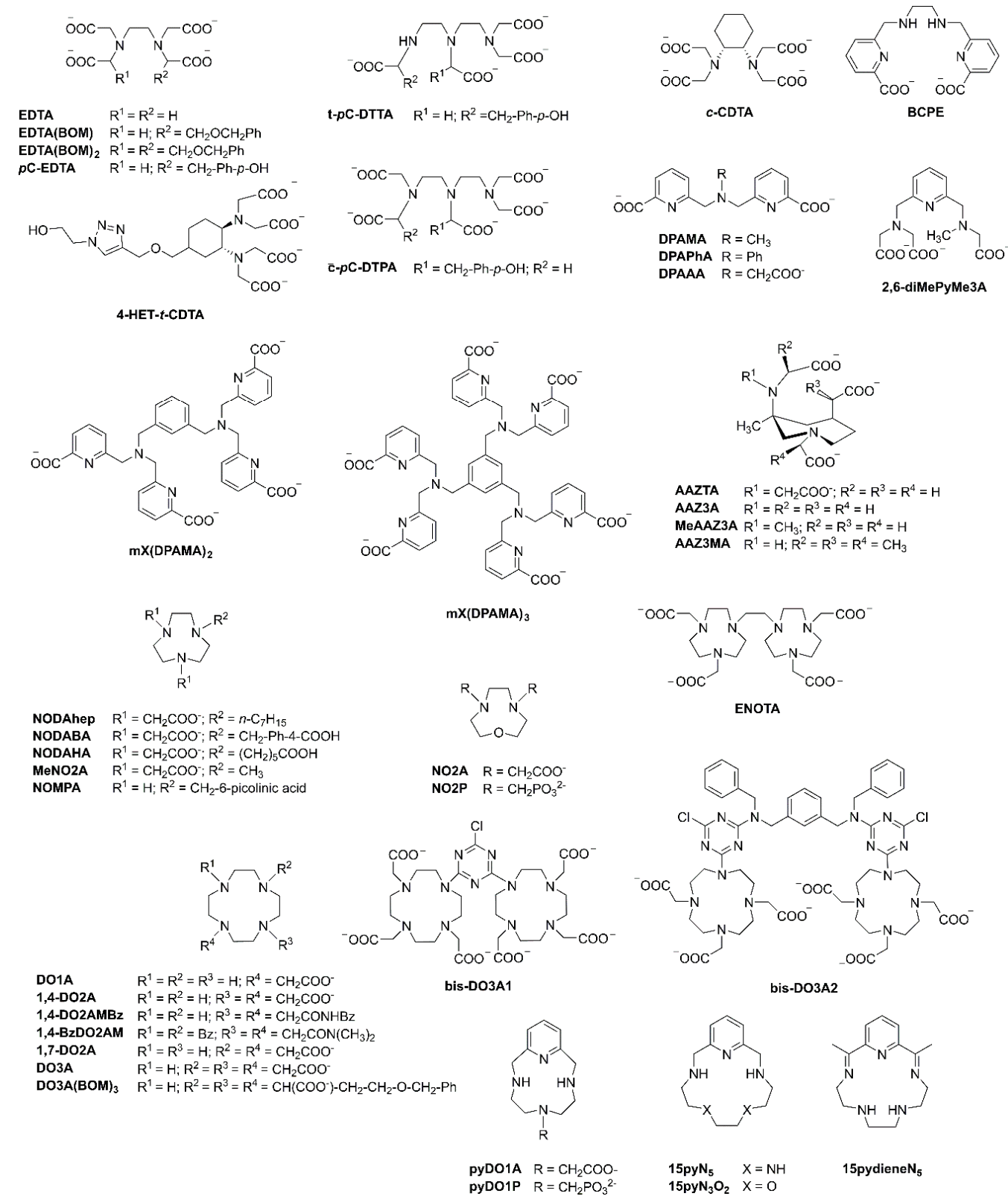

Figure 1. Structures of the organic ligands of the $\mathrm{Mn}^{2+}$ complexes mentioned in Table 1. 
Table 1. Comparison of $q_{\text {lit }}$ with $q_{\text {ref }}$ as calculated with Equations (11) and (12) for the database of $\mathrm{Mn}^{2+}$ complexes. Other parameters of relevance for the relaxivity at $298 \mathrm{~K}$ and hyperfine coupling constants reported in the literature are included.

\begin{tabular}{|c|c|c|c|c|c|c|c|c|c|c|}
\hline Organic Ligand & $q_{\text {lit }}{ }^{a}$ & $\begin{array}{c}r_{1} \mathrm{~b} \\
\left(\mathrm{~s}^{-1} \cdot \mathrm{mM}^{-1}\right)\end{array}$ & $F W$ & $q_{\text {calc }}{ }^{\mathrm{c}}$ & $\begin{array}{l}\tau_{R}{ }^{d} \\
(p s)\end{array}$ & $\begin{array}{c}\tau_{\mathrm{S} 0}^{\mathrm{d}} \\
(\mathrm{ps})\end{array}$ & $\underset{(\mathrm{ns})}{\tau_{\mathrm{M}}^{\mathrm{d}}}$ & $R_{(\AA)}^{R_{\mathrm{MnH}}}{ }^{\mathrm{d}}$ & $\begin{array}{l}\left|A_{\mathrm{O}} / \hbar\right|^{\mathrm{d}} \\
\left(10^{6} \mathrm{rad} / \mathrm{s}\right)\end{array}$ & Ref. \\
\hline DOTA & 0.0 & 2.76 & 455.3 & 0.4 & - & - & - & - & - & [28] \\
\hline DTPA & 0.0 & 2.30 & 390.2 & 0.4 & - & - & - & - & - & [30] \\
\hline $1,7-\mathrm{DO} 2 \mathrm{~A}$ & 0.0 & 2.53 & 341.3 & 0.4 & - & 152 & - & - & - & [31] \\
\hline NOTA & 0.0 & 2.30 & 356.2 & 0.4 & - & - & - & - & - & [28] \\
\hline AAZTA & 0.0 & 2.53 & 412.3 & 0.4 & - & 148 & - & - & - & [33] \\
\hline c- $p$ C-DTPA & 0.0 & 3.02 & 492.4 & 0.4 & - & 161 & - & - & - & [34] \\
\hline t- $p$ C-DTTA & 0.0 & 2.55 & 510.4 & 0.4 & - & 108 & - & - & - & [34] \\
\hline $\mathrm{DO} 3 \mathrm{~A}(\mathrm{BOM})_{3}$ & 0.0 & 2.55 & 758.7 & 0.3 & - & 135 & - & - & - & [35] \\
\hline bis-DO3A1 & 0.0 & 2.27 & 837.8 & 0.3 & - & 93 & - & - & - & [36] \\
\hline $1,4-\mathrm{DO} 2 \mathrm{~A}$ & 0.9 & 4.50 & 359.3 & 0.7 & 46.0 & 74 & 88.2 & 2.83 & 43.0 & [31] \\
\hline DO1A & 1.0 & 4.04 & 302.3 & 0.7 & 22.0 & 88 & 0.168 & 2.83 & 39.4 & [31] \\
\hline $\mathrm{MeNO}_{2} \mathrm{~A}$ & 1.0 & 4.96 & 330.2 & 0.9 & 36.0 & 101 & 1.60 & 2.77 & 46.0 & [37] \\
\hline pyDO1A & 1.0 & 3.54 & 336.3 & 0.6 & 23.0 & 449 & 0.330 & - & - & [38] \\
\hline NOMPA & 1.0 & 6.21 & 336.3 & 1.1 & 51.2 & 129 & 0.361 & 2.77 & -73.3 & [39] \\
\hline EDTA & 1.0 & 5.41 & 361.2 & 0.9 & 56.0 & 81 & 2.12 & 2.83 & 40.5 & [31] \\
\hline EDTA & 1.0 & 5.41 & 361.2 & 0.9 & 57.0 & 81 & 2.12 & 2.83 & 40.5 & [31] \\
\hline EDTA & 1.0 & 5.81 & 361.2 & 1.0 & - & - & - & - & - & [30] \\
\hline EDTA & 1.0 & 5.60 & 361.2 & 0.9 & - & - & - & - & - & [29] \\
\hline pyD01P & 1.0 & 3.84 & 371.2 & 0.6 & 38.6 & 36 & 0.565 & - & 39.9 & [38] \\
\hline $\mathrm{NO} 2 \mathrm{P}$ & 1.0 & 8.03 & 387.1 & 1.3 & 103.0 & 87 & 83.333 & 2.75 & 33.3 & [40] \\
\hline 2,6-diMePyMe3A & 1.0 & 5.23 & 395.2 & 0.8 & 46.0 & 52 & 0.357 & 2.83 & 26.4 & [41] \\
\hline 1,4-DO2AMBz & 1.0 & 5.67 & 539.6 & 0.8 & 85.0 & 71 & 5.71 & 2.83 & 33.0 & [45] \\
\hline 4-HET-t-CDTA & 1.0 & 6.72 & 570.4 & 0.9 & 104.9 & 56 & 5.68 & 2.83 & 40.0 & [46] \\
\hline 1,4-BzDO2AM & 1.0 & 5.89 & 595.7 & 0.8 & 96.0 & 60 & 3.95 & 2.83 & 31.0 & [45] \\
\hline $\operatorname{EDTA}(\mathrm{BOM})_{2}$ & 1.0 & $7.25^{\mathrm{e}}$ & 629.5 & 0.9 & 110.8 & 84 & 7.60 & 2.90 & - & [35] \\
\hline ENOTA & 1.0 & $6.46^{\mathrm{f}}$ & 658.5 & 0.8 & 85.0 & 4317 & 18.2 & 2.75 & 5.2 & [23] \\
\hline NO2A & 1.4 & 5.67 & 317.2 & 1.0 & 22.0 & 160 & 0.840 & 2.75 & 33.3 & [40] \\
\hline $15 \mathrm{pyN}_{5}$ & 2.0 & 9.64 & 340.3 & 1.7 & 28.3 & 8710 & 14.5 & 2.81 & 38.6 & [47] \\
\hline 15 pyN $_{3} \mathrm{O}_{2}$ & 2.0 & 11.52 & 342.3 & 2.0 & 40.3 & 7174 & 263 & 2.81 & 38.6 & [47] \\
\hline 15 pydieneN $N_{5}$ & 2.0 & 14.20 & 364.3 & 2.3 & - & - & - & - & - & [30] \\
\hline DPAMA & 2.0 & 11.25 & 390.3 & 1.8 & 47.8 & 167 & 3.27 & 2.74 & - & [32] \\
\hline DPAPhA & 2.0 & 11.65 & 452.3 & 1.7 & 81.0 & 87 & 17.9 & 2.78 & 25.0 & [43] \\
\hline $\mathrm{mX}(\mathrm{DPAMA})_{2}$ & 2.0 & 17.65 & 854.6 & 2.1 & 95.8 & 183 & 32.7 & 2.74 & - & [32] \\
\hline $\mathrm{mX}(\mathrm{DPAMA})_{3}$ & 2.0 & 19.72 & 1243.8 & 2.2 & 136.0 & 173 & 32.7 & 2.74 & - & [32] \\
\hline none & 6.0 & $19.52^{\mathrm{h}}$ & 163.0 & 5.6 & 30.0 & 26042 & 35.5 & 2.83 & 34.6 & [13] \\
\hline none & 6.0 & $20.98^{i}$ & 163.0 & 6.0 & - & - & - & - & - & [30] \\
\hline
\end{tabular}

${ }^{a}$ As reported in reference. ${ }^{b}$ Measured in reported NMRD profile at Larmor frequency $(L F)=0.01 \mathrm{MHz}$, unless stated otherwise. ${ }^{c}$ As calculated with Equations (11) and (12). ${ }^{d}$ Reported values evaluated from analysis of Nuclear Magnetic Relaxation Dispersion (NMRD) and ${ }^{17} \mathrm{O}$ NMRD data. ${ }^{\mathrm{e}} L F=0.03 \mathrm{MHz} .{ }^{\mathrm{f}} L F=1.14 \mathrm{MHz} .{ }^{\mathrm{g}} L F=0.02 \mathrm{MHz}$. ${ }^{\mathrm{h}} L F=1.00 \mathrm{MHz} .{ }^{\mathrm{I}} L F=1.35 \mathrm{MHz}$.

For the evaluation of $q$, we focused our attention to the low field parts of the NMRD profiles. Below the dispersion at $L F \approx 10 \mathrm{MHz}$, the profiles always had a plateau, where $r_{1}$ was rather large and almost independent of $L F$, which allows an accurate measurement of $r_{1}$. At low field, $r_{1}$ was dominated by $q$ and the electronic relaxation, whereas at higher field strengths the nuclear relaxation dominated, which in turn was dominated by $q, \tau_{\mathrm{R}}$, and $\tau_{\mathrm{M}}$. This might lead to local maxima in the profile for high molecular weight compounds and relatively low relaxivities for low molecular compounds [2]. 
Values of $r_{1}$ at $0.01 \mathrm{MHz}$ were measured in the profiles with a single dispersion. In the profiles for $\left[\mathrm{Mn}\left(\mathrm{H}_{2} \mathrm{O}\right)_{6}\right]^{2+}$ and $\left[\mathrm{Mn}_{2}(\mathrm{ENOTA})\left(\mathrm{H}_{2} \mathrm{O}\right)_{2}\right]$, the $r_{1}$ was measured at about $1 \mathrm{MHz}$ (at the plateau behind the first dispersion), where the scalar contribution may be neglected.

Figure 2 displays a plot of the collected low field $r_{1}$-values versus the reported $q$ values for the $\mathrm{Mn}^{2+}$ complexes concerned $\left(q_{\text {lit }}\right)$. Many of the $q_{\text {lit }}$ values were obtained by applying a combination of several of the methods described above. For $q=0$, the datapoints are in a narrow range of $r_{1}$-values around an average of $2.4 \pm 0.2 \mathrm{~s}^{-1} \cdot \mathrm{mM}^{-1}$. This value can therefore be applied as a good estimate of the outer sphere contribution of all $\mathrm{Mn}^{2+}$ complexes. For $q>0$, Figure 2 clearly shows that the ranges of $r_{1}$ values for various $q$-values overlap. Hence $r_{1}$ ranges alone cannot be applied for the evaluation of $q$.

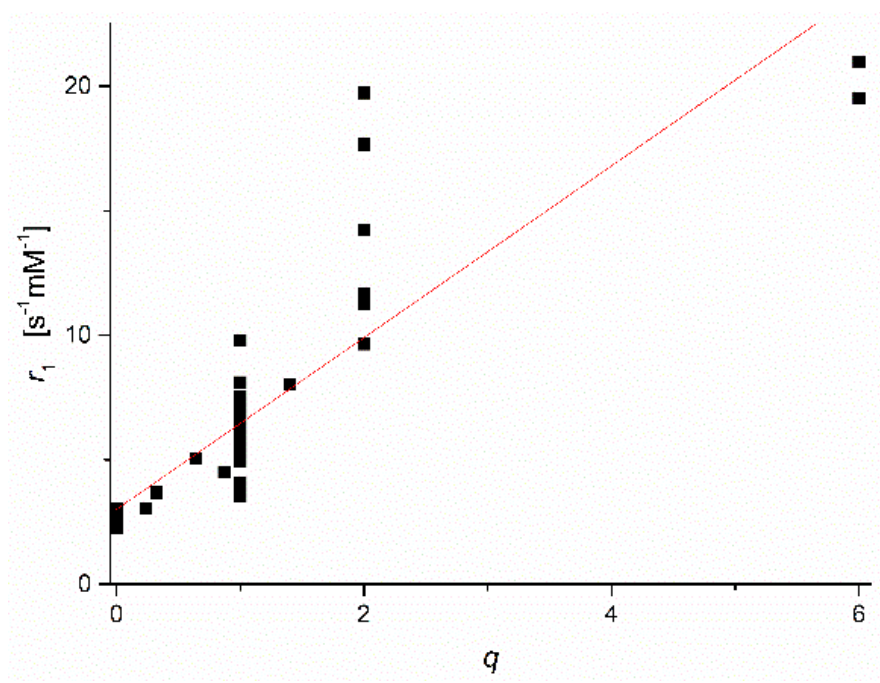

Figure 2. Plot of low field $r_{1}$ versus $q$-values collected from previously reported publications on $\mathrm{Mn}^{2+}$-complexes.

A closer inspection of the structures corresponding with datapoints at $q=1$ and $q=2$ indicates that $r_{1}$ increased with the molecular volume of the $\mathrm{Mn}^{2+}$-complexes at each $q$, which suggests that the $r_{1}$ at low field also depended on the rotational correlation time $\left(\tau_{R}\right)$. Therefore, we next considered the datapoints for $q \neq 0$. For these data, $r_{1} / q$ appeared not to be linearly proportional to the molecular weight $(F W)$. Regression of $r_{1} / q$ as a function of $F W$ with the computer program CurveExpert 1.4 using all in-built models afforded a good fit with Equation (11):

$$
y=9.16\left\{1-\exp \left(-2.97 \times F W \times 10^{-3}\right)\right\}
$$

The hydration number can be calculated with Equation (12):

$$
q_{\text {calc }}=\frac{r_{1}}{y}
$$

Figure 3 shows the good agreement between the calculated hydration numbers $\left(q_{\mathrm{calc}}\right)$ and the values mentioned in the publications from which the $r_{1}$ values were taken $\left(q_{\text {lit }}\right)$. Fractional $q$ numbers are also correctly predicted. From Figure 3 , the accuracy of $q_{\text {calc }}$ is estimated to be \pm 0.4 . The good agreement between all calculated and reported $q$ values indicates that the applied previously reported $q$ values are correct. Moreover, it indicates that $q$ and $F W$ are the main parameters that determined the relaxivity; apparently, the influence of other parameters was rather small. This is surprising, since $r_{1}$ at low $L F$ was expected to be dominated by the electronic relaxation. Even the $q$-values of complexes with relatively large $\tau_{\mathrm{S} 0}$-values $\left(\mathrm{Mn}_{2}(\right.$ ENOTA $)\left(\mathrm{H}_{2} \mathrm{O}\right)_{2}$, $\left[\mathrm{Mn}\left(15 \mathrm{pyN}_{5}\right)\left(\mathrm{H}_{2} \mathrm{O}\right)\right]^{2+}$, $\left[\mathrm{Mn}\left(15 \mathrm{pyN}_{3} \mathrm{O}_{2}\right)\left(\mathrm{H}_{2} \mathrm{O}\right)_{2}\right]^{2+}$, and $\left[\mathrm{Mn}\left(\mathrm{H}_{2} \mathrm{O}\right)_{6}\right]^{2+}$, see Table 1) seem to be predicted correctly. To explain this, simulations of $r_{1}$ at $L F$ 
$=0.01 \mathrm{MHz}$ as a function of $\tau_{\mathrm{M}}, \tau_{\mathrm{R}}$, and $\tau_{\mathrm{S} 0}$ were made using the SBM equations. Figure 4 shows, for example, the simulations for typical $q=1 \mathrm{Mn}^{2+}$ complexes. Figure $4 \mathrm{~A}$ shows that $r_{1}$ is unsensitive to variations in $\tau_{\mathrm{M}}$; however, it is strongly dependent on $\tau_{R}$, and Figure $4 \mathrm{~B}$ shows that $r_{1}$ was only very sensitive to variations of $\tau_{\mathrm{S} 0}$ for complexes for which $\tau_{\mathrm{R}}>150 \mathrm{ps}$. The complexes in the database used to deduce Equations (11) and (12) are exclusively of low and medium molecular weight compounds $(F W<1250)$. The simulations in Figure 4 confirmed that for those complexes, $r_{1}$ can be expected to be insensitive to variations in electronic relaxation rates and $\tau_{\mathrm{M}}$. However, it may be expected that these Equations are no longer valid for high molecular weight $\mathrm{Mn}^{2+}$ complexes. However, in those cases, $q$ can generally be estimated from low molecular analogs.

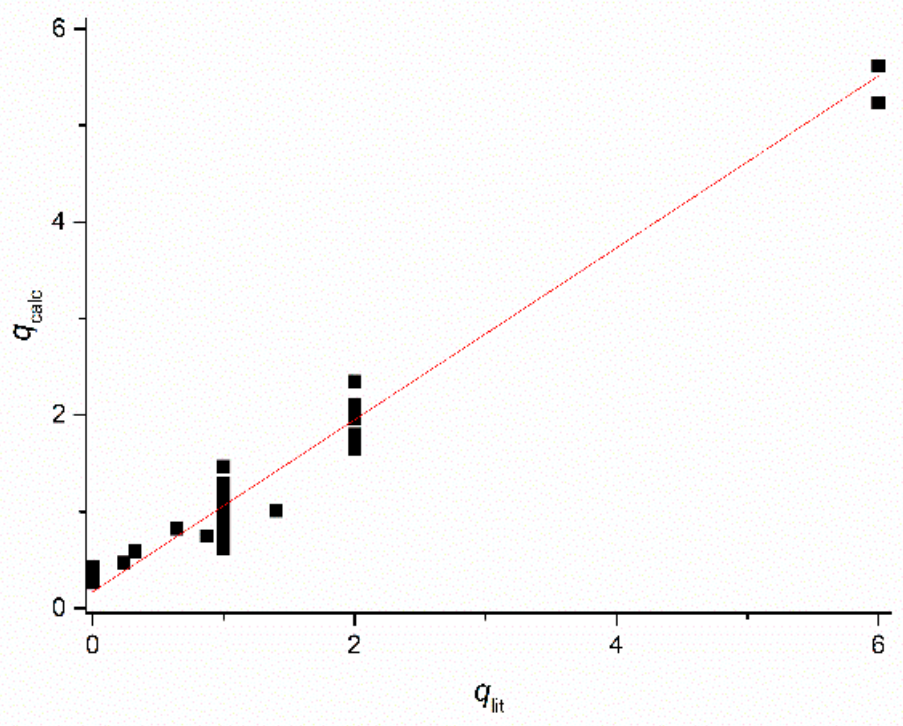

Figure 3. Plot of the hydration number for the $\mathrm{Mn}^{2+}$-complexes mentioned in Table 1 calculated with Equations (1) and (2) $\left(q_{\text {calc }}\right)$ versus the corresponding values reported in the literature $\left(q_{\text {lit }}\right)$.

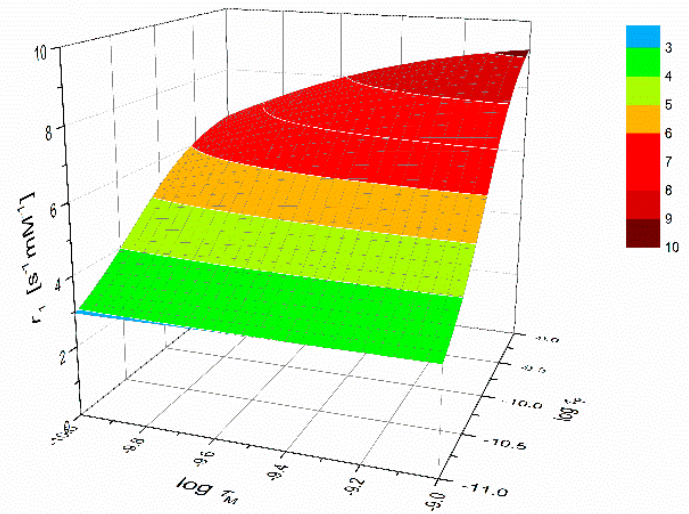

B

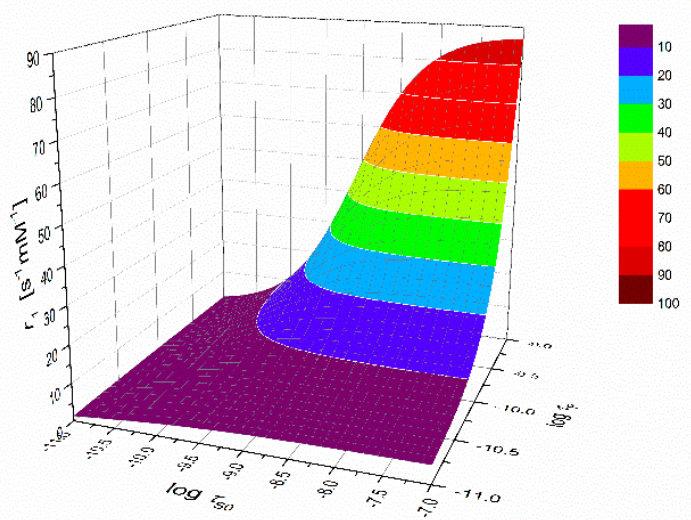

Figure 4. Representations of simulations of $r_{1}$ at $L F=0.01 \mathrm{MHz}(\mathbf{A})$ as function of $\tau_{\mathrm{M}}$ and $\tau_{\mathrm{R}}$ and (B) as function of $\tau_{\mathrm{S} 0}$ and $\tau_{\mathrm{R}}$. Solomon-Bloembergen-Morgan (SBM) Equations (1)-(10) were applied using the following parameters: $q=1, r_{\mathrm{MnH}}=2.83 \AA, D_{\mathrm{MnH}}=2.31 \times 10^{-9} \mathrm{~m}^{2} \cdot \mathrm{s}^{-1}, a_{\mathrm{MnH}}=3.6 \AA$.

An attempt to apply a similar procedure for the evaluation of $q$ from $r_{1}$ values at $L F=60 \mathrm{MHz}$ resulted in unreasonable $q_{\text {calc }}$ values that deviated substantially from $q_{\text {lit }}$. 


\section{Methods}

The relaxivities were extracted from published NMRD profiles using the computer program WebPlotDigitizer, version 4.1 [48]. Equation (11) was selected with the computer program CurveExpert, version 1.4 [49].

\section{Conclusions}

An inspection of published ${ }^{1} \mathrm{H}$ NMRD profiles of $\mathrm{Mn}^{2+}$-complexes of low and medium molecular weights $(F W<1250)$ shows that the magnitudes of $r_{1}$ at $L F \leq 0.1 \mathrm{MHz}$ is dominated by the parameters $q$ and $\tau_{\mathrm{R}}$. Using a dataset of 49 published NMRD profiles as learning set, Equations (11) and (12) were evaluated for a quick and reliable estimation of $q$ from $r_{1}$ values at $L F \leq 0.1 \mathrm{MHz}$ and the molecular weight of the complex.

Author Contributions: Conceptualization, J.A.P. and C.F.G.C.G.; validation, J.A.P. and C.F.G.C.G.; formal analysis, J.A.P.; writing-review and editing, J.A.P. and C.F.G.C.G.

Funding: This research received no external funding.

Conflicts of Interest: The authors declare no conflict of interest.

\section{References}

1. Merbach, A.E.; Helm, L.; Tóth, É. The Chemistry of Contrast Agents in Medical Magnetic Resonance Imaging, 2nd ed.; John Wiley \& Sons, Ltd.: Chichester, UK, 2013; ISBN 0-471-60778-9.

2. Caravan, P.; Ellison, J.J.; McMurry, T.J.; Lauffer, R.B. Gadolinium(III) chelates as MRI contrast agents: Structure, dynamics, and applications. Chem. Rev. 1999, 99, 2293-2352. [CrossRef] [PubMed]

3. Caravan, P.; Farrar, C.T.; Frullano, L.; Uppal, R. Influence of molecular parameters and increasing magnetic field strength on relaxivity of gadolinium- and manganese-based $\mathrm{T}_{1}$ contrast agents. Contrast Media Mol. Imaging 2009, 4, 89-100. [CrossRef] [PubMed]

4. Baranyai, Z.; Brücher, E.; Uggeri, F.; Maiocchi, A.; Tóth, I.; Andrási, M.; Gáspár, A.; Zékány, L.; Aime, S. The role of equilibrium and kinetic properties in the dissociation of Gd[DTPA-bis(methylamide)] (omniscan) at near to physiological conditions. Chem. Eur. J. 2015, 21, 4789-4799. [CrossRef] [PubMed]

5. Brücher, E.; Tircsó, G.; Baranyai, Z.; Kovács, Z.; Sherry, A.D. Stability and toxicity of contrast agents. In The Chemistry of Contrast Agents in Medical Magnetic Resonance Imaging; Merbach, A.E., Helm, L., Tóth, É., Eds.; John Wiley \& Sons Ltd.: Chichester, UK, 2013; pp. 157-208.

6. Kanal, E.; Tweedle, M.F. Residual or retained gadolinium: Practical implications for radiologists and our patients. Radiology 2015, 275, 630-634. [CrossRef] [PubMed]

7. Kanda, T.; Fukusato, T.; Matsuda, M.; Toyoda, K.; Oba, H.; Kotoku, J.I.; Haruyama, T.; Kitajima, K.; Furui, S. Gadolinium-based contrast agent accumulates in the brain even in subjects without severe renal dysfunction: Evaluation of autopsy brain specimens with inductively coupled plasma mass spectroscopy. Radiology 2015, 276, 228-232. [CrossRef] [PubMed]

8. Pullicino, R.; Radon, M.; Biswas, S.; Bhojak, M.; Das, K. A review of the current evidence on gadolinium deposition in the brain. Clin. Neuroradiol. 2018, 128, 159-169. [CrossRef] [PubMed]

9. Haynes, W.M. CRC Handbook of Chemistry and Physics; CRC Press: Boca Raton, FL, USA, 2014; ISBN 9781498754286.

10. Alpoim, M.C.; Urbano, A.M.; Geraldes, C.F.G.C.; Peters, J.A. Determination of the number of inner-sphere water-molecules in lanthanide(III) polyaminocarboxylate complexes. J. Chem. Soc. Dalton Trans. 1992, 463-467. [CrossRef]

11. Djanashvili, K.; Peters, J.A. How to determine the number of inner-sphere water molecules in lanthanide(III) complexes by ${ }^{17} \mathrm{O}$ NMR spectroscopy. A technical note. Contrast Media Mol. Imaging 2007, 2, 67-71. [CrossRef] [PubMed]

12. Beeby, A.; Clarkson, I.M.; Dickins, R.S.; Faulkner, S.; Parker, D.; Royle, L.; de Sousa, A.S.; Williams, J.A.G.; Woods, M. Non-radiative deactivation of the excited states of europium, terbium and ytterbium complexes by proximate energy-matched $\mathrm{OH}, \mathrm{NH}$ and $\mathrm{CH}$ oscillators: An improved luminescence method for establishing solution hydration states. J. Chem. Soc. Perkin Trans. 1999, 2, 493-504. [CrossRef] 
13. Esteban-Gómez, D.; Cassino, C.; Botta, M.; Platas-Iglesias, C. ${ }^{17} \mathrm{O}$ and ${ }^{1} \mathrm{H}$ relaxometric and DFT study of hyperfine coupling constants in $\left[\mathrm{Mn}\left(\mathrm{H}_{2} \mathrm{O}\right)_{6}\right]^{2+}$. RSC Adv. 2014, 4, 7094-7103. [CrossRef]

14. Póta, K.; Garda, Z.; Kálmán, F.K.; Barriada Pereira, J.L.; Esteban-Gómez, D.; Platas-Iglesias, C.; Tóth, I.; Brücher, E.; Tircsó, G. Making a next step toward inert $\mathrm{Mn}^{2+}$ complexes of open-chain ligands: The case of the rigid PhDTA ligand. New J. Chem. 2018, 42, 8001-8011. [CrossRef]

15. Leigh, J.S., Jr. Relaxation times in systems with chemical exchange. Exact solutions. J. Magn. Reson. 1971, 4, 308-311. [CrossRef]

16. Swift, T.J.; Connick, R.E. NMR (nuclear magnetic resonance)-relaxation mechanisms of O17 in aqueous solutions of paramagnetic cations and the lifetime of water molecules in the first coordination sphere. J. Chem. Phys. 1962, 37, 307-320. [CrossRef]

17. Solomon, I. Relaxation processes in a system of two spins. Phys. Rev. 1955, 99, 559-565. [CrossRef]

18. Bloembergen, N. Proton relaxation times in paramagnetic solutions. J. Chem. Phys. 1957, 27, 572-573. [CrossRef]

19. Bloembergen, N.; Morgan, L.O. Proton relaxation times in paramagnetic solutions. Effects of electron spin relaxation. J. Chem. Phys. 1961, 34, 842-850. [CrossRef]

20. Freed, J.H. Dynamic effects of pair correlation functions on spin relaxation by translational diffusion in liquids. II. Finite jumps and independent $T_{1}$ processes. J. Chem. Phys. 1978, 68, 4034-4037. [CrossRef]

21. Bertini, I.; Briganti, F.; Xia, Z.; Luchinat, C. Nuclear magnetic relaxation dispersion studies of hexaaquo manganese(II) ions in water-glycerol mixtures. J. Magn. Reson. 1993, 101, 198-201. [CrossRef]

22. Koenig, S.H.; Brown, R.D.; Studebaker, J. On the interpretation of solvent proton magnetic relaxation data with particular application to the structure of the active site of Mn-carboxypeptidase A. In Cold Spring Harbor Symposia on Quantitative Biology; Cold Spring Harbor Laboratory Press: Cold Spring Harbor, New York, NY, USA, 1971; Volume 36, pp. 551-559.

23. Balogh, E.; He, Z.; Hsieh, W.; Liu, S.; Tóth, É. Dinuclear complexes formed with the triazacyclononane derivative ENOTA ${ }^{4-}$ : High-pressure ${ }^{17} \mathrm{O}$ NMR evidence of an associative water exchange on $\left[\mathrm{Mn}_{2}{ }_{2}\right.$ (ENOTA) $\left(\mathrm{H}_{2} \mathrm{O}\right)_{2}$ ]. Inorg. Chem. 2007, 46, 238-250. [CrossRef] [PubMed]

24. Helm, L. Relaxivity in paramagnetic systems: Theory and mechanism. Prog. Nucl. Magn. Reson. Spectrosc. 2006, 49, 45-64. [CrossRef]

25. Belorizky, E.; Fries, P.H.; Helm, L.; Kowalewski, J.; Kruk, D.; Sharp, R.R.; Westlund, P.O. Comparison of different methods for calculating the paramagnetic relaxation enhancement of nuclear spins as a function of the magnetic field. J. Chem. Phys. 2008, 128, 052315. [CrossRef] [PubMed]

26. Troughton, J.S.; Greenfield, M.T.; Greenwood, J.M.; Dumas, S.; Wiethoff, A.J.; Wang, J.; Spiller, M.; McMurry, T.J.; Caravan, P. Synthesis and evaluation of a high relaxivity manganese(II)-based MRI contrast agent. Inorg. Chem. 2004, 43, 6313-6323. [CrossRef] [PubMed]

27. Belorizky, E.; Fries, P.H. Simple analytical approximation of the longitudinal electronic relaxation rate of Gd(III) complexes in solutions. Phys. Chem. Chem. Phys. 2004, 6, 2341-2351. [CrossRef]

28. Geraldes, C.F.G.C.; Sherry, A.D.; Brown, R.D., III; Koenig, S.H. Magnetic field dependence of solvent proton relaxation rates induced by gadolinium(3+) and manganese(2+) complexes of various polyaza macrocyclic ligands: Implications for NMR imaging. Magn. Reson. Med. 1986, 3, 242-250. [CrossRef] [PubMed]

29. Koenig, S.H.; Brown, R.D., III. Relaxometry of magnetic resonance imaging contrast agents. Magn. Reson. Аnпu. 1987, 263-286.

30. Jackels, S.C.; Durham, M.M.; Newton, J.E.; Henninger, T.C. Aqueous proton NMR relaxation enhancement by manganese(II) macrocyclic complexes: Structure-relaxivity relationships. Inorg. Chem. 1992, 31, 234-239. [CrossRef]

31. Rolla, G.A.; Platas-Iglesias, C.; Botta, M.; Tei, L.; Helm, L. ${ }^{1} \mathrm{H}$ and ${ }^{17} \mathrm{O}$ NMR relaxometric and computational study on macrocyclic Mn(II) complexes. Inorg. Chem. 2013, 52, 3268-3279. [CrossRef] [PubMed]

32. Forgács, A.; Botta, M.; Regueiro-Figueroa, M.; Barriada, J.L.; Esteban-Gómez, D.; de Blas, A.; Rodríguez-Blas, T.; Platas-Iglesias, C. Mono-, bi-, and trinuclear bis-hydrated $\mathrm{Mn}(2+)$ complexes as potential MRI contrast agents. Inorg. Chem. 2015, 54, 9576-9587. [CrossRef] [PubMed]

33. Tei, L.; Gugliotta, G.; Fekete, M.; Kalman, F.K.; Botta, M. Mn(II) complexes of novel hexadentate AAZTA-like chelators: A solution thermodynamics and relaxometric study. Dalton Trans. 2011, 40, 2025-2032. [CrossRef] [PubMed] 
34. Rolla, G.A.; Tei, L.; Fekete, M.; Arena, F.; Gianolio, E.; Botta, M. Responsive Mn(II) complexes for potential applications in diagnostic magnetic resonance imaging. Bioorg. Med. Chem. 2011, 19, 1115-1122. [CrossRef] [PubMed]

35. Aime, S.; Anelli, L.; Botta, M.; Brocchetta, M.; Canton, S.; Fedeli, F.; Gianolio, E.; Terreno, E. Relaxometric evaluation of novel manganese(II) complexes for application as contrast agents in magnetic resonance imaging. J. Biol. Inorg. Chem. 2002, 7, 58-67. [CrossRef] [PubMed]

36. Artali, R.; Baranyai, Z.; Botta, M.; Giovenzana, G.B.; Maspero, A.; Negri, R.; Palmisano, G.; Sisti, M.; Tollari, S. Solution thermodynamics, computational and relaxometric studies of ditopic DO3A-based Mn(II) complexes. New J. Chem. 2015, 39, 539-547. [CrossRef]

37. Patinec, V.; Rolla, G.A.; Botta, M.; Tripier, R.; Esteban-Gómez, D.; Platas-Iglesias, C. Hyperfine coupling constants on inner-sphere water molecules of a triazacyclononane-based $\mathrm{Mn}$ (II) complex and related systems relevant as mri contrast agents. Inorg. Chem. 2013, 52, 11173-11184. [CrossRef] [PubMed]

38. Drahoš, B.; Kotek, J.; Císařová, I.; Hermann, P.; Helm, L.; Lukeš, I.; Tóth, É. Mn ${ }^{2+}$ complexes with 12-membered pyridine based macrocycles bearing carboxylate or phosphonate pendant arm: Crystallographic, thermodynamic, kinetic, redox, and ${ }^{1} \mathrm{H} /{ }^{17} \mathrm{O}$ relaxation studies. Inorg. Chem. 2011, 50, 12785-12801. [CrossRef] [PubMed]

39. Molnár, E.; Camus, N.; Patinec, V.; Rolla, G.A.; Botta, M.; Tircsó, G.; Kálmán, F.K.; Fodor, T.; Tripier, R.; Platas-Iglesias, C. Picolinate-containing macrocyclic $\mathrm{Mn}^{2}+$ complexes as potential MRI contrast agents. Inorg. Chem. 2014, 53, 5136-5149. [CrossRef] [PubMed]

40. Drahoš, B.; Pniok, M.; Havlí̌ková, J.; Kotek, J.; Císařová, I.; Hermann, P.; Lukeš, I.; Tóth, É. Mn²+ complexes of 1-oxa-4,7-diazacyclononane based ligands with acetic, phosphonic and phosphinic acid pendant arms: Stability and relaxation studies. Dalton Trans. 2011, 40, 10131-10146. [CrossRef] [PubMed]

41. Laine, S.; Bonnet, C.S.; Kálmán, F.K.; Garda, Z.; Pallier, A.; Caillé, F.; Suzenet, F.; Tircsó, G.; Tóth, É. Mn²+ complexes of open-chain ligands with a pyridine backbone: Less donor atoms lead to higher kinetic inertness. New J. Chem. 2018, 42, 8012-8020. [CrossRef]

42. De Sá, A.; Bonnet, C.S.; Geraldes, C.F.G.C.; Tóth, É.; Ferreira, P.M.T.; André, J.P. Thermodynamic stability and relaxation studies of small, triaza-macrocyclic Mn(II) chelates. Dalton Trans. 2013, 42, 4522-4532. [CrossRef] [PubMed]

43. Forgács, A.; Pujales-Paradela, R.; Regueiro-Figueroa, M.; Valencia, L.; Esteban-Gómez, D.; Botta, M.; Platas-Iglesias, C. Developing the family of picolinate ligands for $\mathrm{Mn}^{2+}$ complexation. Dalton Trans. 2017, 1546-1558. [CrossRef] [PubMed]

44. Molnár, E.; Váradi, B.; Garda, Z.; Botár, R.; Kálmán, F.K.; Tóth, É.; Platas-Iglesias, C.; Tóth, I.; Brücher, E.; Tircsó, G. Remarkable differences and similarities between the isomeric Mn(II)-cis- and trans-1,2-diaminocyclohexane- $N, N, N^{\prime}, N^{\prime}$-tetraacetate complexes. Inorg. Chim. Acta 2018, 472, 254-263. [CrossRef]

45. Forgács, A.; Tei, L.; Baranyai, Z.; Esteban-Gómez, D.; Platas-Iglesias, C.; Botta, M. Optimising the relaxivities of $\mathrm{Mn}^{2+}$ complexes by targeting human serum albumin (HSA). Dalton Trans. 2017, 8494-8504. [CrossRef] [PubMed]

46. Vanasschen, C.; Molnár, E.; Tircsó, G.; Kálmán, F.K.; Tóth, É.; Brandt, M.; Coenen, H.H.; Neumaier, B. Novel cdta-based, bifunctional chelators for stable and inert $\mathrm{Mn}^{\mathrm{II}}$ complexation: Synthesis and physicochemical characterization. Inorg. Chem. 2017, 56, 7746-7760. [CrossRef] [PubMed]

47. Drahoš, B.; Kotek, J.; Hermann, P.; Lukeš, I.; Tóth, É. Mn ${ }^{2+}$ complexes with pyridine-containing 15-membered macrocycles: Thermodynamic, kinetic, crystallographic, and ${ }^{1} \mathrm{H} /{ }^{17} \mathrm{O}$ relaxation studies. Inorg. Chem. 2010, 49, 3224-3238. [CrossRef] [PubMed]

48. Webplotdigitizer. Available online: https://automeris.io/WebPlotDigitizer/ (accessed on 10 August 2018).

49. Curveexpert Basic, Version 2.1.0. Available online: http://www.curveexpert.net (accessed on 10 August 2018).

(C) 2018 by the authors. Licensee MDPI, Basel, Switzerland. This article is an open access article distributed under the terms and conditions of the Creative Commons Attribution (CC BY) license (http:/ / creativecommons.org/licenses/by/4.0/). 